\title{
Technical Note: Alternative in-stream denitrification equation for the INCA-N model
}

\author{
J. R. Etheridge ${ }^{1}$, F. Birgand ${ }^{1}$, M. R. Burchell $\mathrm{II}^{1}$, A. Lepistö ${ }^{2}$, K. Rankinen ${ }^{2}$, and K. Granlund ${ }^{2}$ \\ ${ }^{1}$ North Carolina State University, Department of Biological and Agricultural Engineering Campus Box 7625, \\ Raleigh, North Carolina, USA \\ ${ }^{2}$ Finnish Environment Institute, P.O. Box 140, 00251, Helsinki, Finland
}

Correspondence to: F. Birgand (birgand@ncsu.edu)

Received: 16 July 2013 - Published in Hydrol. Earth Syst. Sci. Discuss.: 29 November 2013

Revised: 9 March 2014 - Accepted: 27 March 2014 - Published: 16 April 2014

\begin{abstract}
The Integrated Catchment model for Nitrogen (INCA-N) is a semi-distributed, process based model that has been used to model the impacts of land use, climate, and land management changes on hydrology and nitrogen loading. An observed problem with the INCA-N model is reproducing low nitrate-nitrogen concentrations during the summer growing season in some catchments. In this study, the current equation used to simulate the rate of in-stream denitrification was replaced with an alternate equation that uses a mass transfer coefficient and the stream bottom area. The results of simulating in-stream denitrification using the two different methods were compared for a one year simulation period of the Yläneenjoki catchment in Finland. The alternate equation (Nash-Sutcliffe efficiency $=0.61)$ simulated concentrations during the periods of the growing season with the lowest flow that were closer to the observed concentrations than the current equation (Nash-Sutcliffe efficiency $=0.60$ ), but the results were mixed during other portions of the year. The results of the calibration and validation of the model using the two equations show that the alternate equation will simulate lower nitrate-nitrogen concentrations during the growing season when compared to the current equation, but promote investigation into other errors in the model that may be causing inaccuracies in the modeled concentrations.
\end{abstract}

\section{Introduction}

Catchment scale nutrient models can be used to predict the effect of changing land use and climate on nutrient export. The Integrated Catchment model for Nitrogen (INCA-N) is a catchment scale model that simulates both hydrology and mineral nitrogen processes (Wade et al., 2002; Whitehead et al., 1998). INCA-N has been applied to many European catchments, but one problem has been the overestimation of nitrate-nitrogen $\left(\mathrm{NO}_{3}-\mathrm{N}\right)$ concentrations during the summer growing season (Jarvie et al., 2002; Rankinen et al., 2006). It is assumed that the current equations used in INCA-N to model in-stream denitrification also take into account other retention mechanisms (O'Shea and Wade, 2009), but results indicate that a retention process such as macrophyte uptake is not accurately represented by the current equations for instream denitrification (Jarvie et al., 2002; Rankinen et al., 2006, 2013). Other potential causes of the overestimation of concentrations is too much $\mathrm{NO}_{3}-\mathrm{N}$ being added from other sources such as groundwater (Wade et al., 2006, 2008) or the simulated volume of water in the stream being too low. With some simplification it can be shown that the current equation used to simulate in-stream denitrification assumes that the mass of nitrogen removed via in-stream denitrification varies linearly with the mass of $\mathrm{NO}_{3}-\mathrm{N}$ in the stream (Sect. 2.1). This approach does not take into account the impact of dilution on the concentration gradient that drives the delivery of $\mathrm{NO}_{3}-\mathrm{N}$ to the stream sediments where denitrification is most likely to occur (Reddy et al., 1978).

Birgand et al. (2007) proposed the use of a mass transfer coefficient $(\rho)$ to quantify in-stream $\mathrm{NO}_{3}-\mathrm{N}$ retention in their extensive review of in-stream denitrification in agricultural catchments. The mass transfer coefficient multiplied by the $\mathrm{NO}_{3}-\mathrm{N}$ concentration corresponds to the mass of nitrogen that would be removed from the water above a certain area of stream bed during a defined period of time. Birgand et 
al. (2007) recommended that the mass transfer coefficient be used in streams with $\mathrm{NO}_{3}-\mathrm{N}$ concentrations above $1 \mathrm{mg} \mathrm{L}^{-1}$ based on the premise that above this threshold, the concentration gradient would be in a downward direction in accordance with the mass transfer coefficient theoretical application. The goal of this work was to test the equations proposed by Birgand et al. (2007) to determine their effectiveness in improving the simulation of in-stream $\mathrm{NO}_{3}-\mathrm{N}$ concentrations as the first step in the process of determining/addressing the issue of errors in the simulation of low $\mathrm{NO}_{3}-\mathrm{N}$ concentrations during the growing season in the INCA-N model.

\section{Methods}

\subsection{Estimation of in-stream denitrification as implemented in the INCA-N model}

The INCA-N model is a dynamic model that uses a mass balance approach to track the movement of mineral nitrogen in a catchment (Wade et al., 2002; Whitehead et al., 1998). Wade et al. (2002) described the equations for in-stream denitrification that have been used in the model since version 1.6. INCA-N model version 1.11 .10 was used in this study.

Equation (1) shows how the mass of nitrogen removed through in-stream denitrification is calculated in the INCA-N model:

$m_{\mathrm{INCA}}=\frac{R_{\mathrm{n}} C_{1, t-1} V}{1000}$

where $m_{\mathrm{INCA}}$ is the total mass of nitrogen removed through in-stream denitrification in a single reach $\left(\mathrm{kg} \mathrm{N} d a y^{-1}\right), R_{\mathrm{n}}$ is the temperature adjusted in-stream denitrification rate $\left(\right.$ day $\left.^{-1}\right), C_{1, t-1}$ is the in-stream $\mathrm{NO}_{3}-\mathrm{N}$ concentration on the previous day $\left(\mathrm{mg} \mathrm{L}^{-1}\right)$, and $V$ is the volume of water stored in the reach $\left(\mathrm{m}^{3}\right)$.

The denitrification rate $\left(R_{\mathrm{n}}\right)$ is temperature dependent, so it varies daily. The relation between temperature and the denitrification rate in the INCA-N model are shown in Eq. (2).

$R_{\mathrm{n}}=1.047 R^{(T-20)}$

where $R$ is the process rate before temperature adjustment $\left(\right.$ day $\left.^{-1}\right)$ and $T$ is the in-stream water temperature $\left({ }^{\circ} \mathrm{C}\right)$.

In the model, the water temperature is assumed to be the same as the air temperature, but a minimum water temperature is defined as a model input. In this simulation, the water temperature was not allowed to drop below $0{ }^{\circ} \mathrm{C}$.

The $\mathrm{NO}_{3}-\mathrm{N}$ concentration $\left(C_{1}\right)$ in the INCA-N model is calculated using Eq. (3):

$C_{1}=\frac{1000 m_{\mathrm{r}}}{V}$

where $m_{\mathrm{r}}$ is the mass of $\mathrm{NO}_{3}-\mathrm{N}$ in the stream reach $(\mathrm{kg})$. If $V$ is assumed to be equal to $V_{t-1}$, then Eq. (1) becomes:
$m_{\mathrm{INCA}}=R_{\mathrm{n}} m_{\mathrm{r}, t-1}$

Although $V$ is not always equal to $V_{t-1}$, this simplifying assumption is reasonable except immediately following a large precipitation event. Based on Eq. (4), the simulated mass of nitrogen removed via in-stream denitrification in the INCA$\mathrm{N}$ model varies linearly with the mass of nitrogen in the stream assuming a constant water temperature.

\subsection{In-stream mass balance of $\mathrm{NO}_{3}-\mathrm{N}$ as implemented in the INCA-N model}

Equation (5) describes the in-stream mass balance calculations for $\mathrm{NO}_{3}-\mathrm{N}$ used in INCA-N:

$\frac{\mathrm{d} m_{\mathrm{r}}}{\mathrm{d} t}=m_{\mathrm{in}}-\frac{Q m_{\mathrm{r}, t-1} \times 86400}{V}-m_{\mathrm{INCA}}+\frac{R_{\mathrm{i}} C_{2, t-1} V}{1000}$

where $m_{\text {in }}$ is the $\mathrm{NO}_{3}-\mathrm{N}$ input mass from upstream and nonpoint sources in the watershed $\left(\mathrm{kg} \mathrm{N}\right.$ day $\left.^{-1}\right), Q$ is the reach discharge $\left(\mathrm{m}^{3} \mathrm{~s}^{-1}\right), R_{\mathrm{i}}$ is the temperature adjusted in-stream nitrification rate $\left(\mathrm{day}^{-1}\right)$, and $C_{2, t-1}$ is the in-stream ammonium concentration on the previous day $\left(\mathrm{mg} \mathrm{L}^{-1}\right)$.

\subsection{Estimation of in-stream denitrification using the mass transfer coefficient}

Equation (6) was used to calculate the mass of nitrogen removed by denitrification using the mass transfer coefficient and the stream bottom area. Equation (6) was adapted from Birgand et al. (2007). The $m_{\mathrm{INCA}}$ in Eq. (5) was replaced with the $m_{\text {alt }}$ value to model the in-stream $\mathrm{NO}_{3}-\mathrm{N}$ mass balance:

$m_{\mathrm{alt}}=\frac{\rho_{\mathrm{n}} A C_{1, t-1}}{1000}$

where $m_{\text {alt }}$ is the total mass of nitrogen removed via instream denitrification in a single reach calculated based on the mass transfer coefficient and the stream bottom area $\left(\mathrm{kg} \mathrm{N}_{\text {day }}{ }^{-1}\right), \rho_{\mathrm{n}}$ is the temperature adjusted mass transfer coefficient for nitrogen removal through denitrification $\left(\mathrm{m} \mathrm{day}^{-1}\right)$, and $A$ is the stream bottom area of the reach $\left(\mathrm{m}^{2}\right)$.

The mass transfer coefficient is temperature dependent and is adjusted to temperature variations using an equation similar to Eq. (2). The assumption that the water temperature never drops below $0{ }^{\circ} \mathrm{C}$ was maintained for the mass transfer coefficient.

The equation using the mass transfer coefficient is different from the equation currently used in the INCA-N model because the mass of nitrogen removed via denitrification changes based on the $\mathrm{NO}_{3}-\mathrm{N}$ concentration instead of the mass of $\mathrm{NO}_{3}-\mathrm{N}$ in the stream. The stream bottom area is held constant in the model, which is discussed in Sect. 2.4. Basing the mass of $\mathrm{NO}_{3}-\mathrm{N}$ removed via in-stream denitrification on the $\mathrm{NO}_{3}-\mathrm{N}$ concentration instead of the mass of $\mathrm{NO}_{3}-\mathrm{N}$ in the stream more accurately represents the downward gradient that partially drives the delivery of $\mathrm{NO}_{3}-\mathrm{N}$ to the sediments on the stream bottom where the conditions are most likely to be favorable for denitrification. 


\subsection{Model calibration}

The alternate equation was tested on the portion of the River Yläneenjoki upstream of the Vanhakartano monitoring station for 2004 (Lepistö et al., 2008). The Yläneenjoki catchment is located in southwestern Finland and drains to Lake Pyhäjärvi. The portion of the Yläneenjoki catchment that was modeled was divided into 4 sub-catchments based on previous model applications (Lepistö et al., 2008; Etheridge et al., 2014). The modeled area was $197 \mathrm{~km}^{2}$ with $33 \%$ of the land being in agricultural production. The main reach of the River Yläneenjoki has a length of $29 \mathrm{~km}$ in the modeled area.

The hydrology portion of the model was calibrated first, followed by the nitrogen portion of the model using the methods described in Granlund et al. (2004) and Etheridge et al. (2014). The hydrology portion of the model was calibrated to continuous flow data at the Vanhakartano monitoring station by adjusting the flow velocity parameters and time constants for the soil and groundwater zones. The nitrogen portion of the model was calibrated such that the instream nutrient concentrations followed the dynamics of the observed concentrations and were of similar magnitude. This was done by adjusting the nutrient process rates in the model. Data available related to nitrogen process rates ranging from fertilizer application data to rates of denitrification measured experimentally were used to reduce uncertainty in model results. More details about the Yläneenjoki Catchment and the general process used to calibrate the model can be found in Etheridge et al. (2014).

The in-stream denitrification and nitrification are the final two processes that alter nitrogen in the INCA-N model, so it was possible to change the in-stream denitrification calculations without changing the results from any other portion of the model. The order of calculations in INCA-N allowed the alternate equation calculations to be completed using a spreadsheet instead of altering the model code. Simulations with the alternate in-stream denitrification equation were done using Excel 2007 (Microsoft, Redmond, WA, USA). Equation (5) is the in-stream mass balance equation for $\mathrm{NO}_{3}-\mathrm{N}$ in the model. The input mass of $\mathrm{NO}_{3}-\mathrm{N}\left(m_{\mathrm{in}}\right)$, the reach discharge $(Q)$, the reach volume $(V)$, and the mass of nitrogen that is nitrified in the reach are all outputs of the model. These model outputs were taken directly from the calibrated model and were not altered in this work. The primary change that was made was replacing $m_{\text {INCA }}$ with $m_{\text {alt }}$ in Eq. (5), which changes the concentration of $\mathrm{NO}_{3}-\mathrm{N}$ in the stream.

To make the calculations using the alternate equation, the stream bottom area $(A)$ of the modeled reach was estimated using ArcGIS (ESRI, Redlands, CA, USA). The main sources of data were a raster map ( $1 \mathrm{~m}$ resolution) of all of the water areas in Finland and a map showing the streamline of the modeled reach. A buffer was created around the modeled streamline using the analysis tools in ArcGIS. All of the water area from the raster map located within this buffer was considered the stream bottom area input to the model. The stream bottom areas that were used in this simulation were $20000,80000,200000$, and $160000 \mathrm{~m}^{2}$ for the sub-catchments moving from upstream to downstream. This method may overestimate the stream bottom area of the primary reach as it includes both the stream bottom and the banks in the projected area. This error was considered reasonable because the entire stream bottom in the catchment was not included, but denitrification and other retention processes occur in the tributaries that feed the main channel.

Assuming a constant stream bottom area throughout the modeling period was not an ideal representation of the physical system because the stream width (i.e., submerged width of the stream) will increase with increasing depth and flow. This simplifying assumption was made so that extensive collection of channel dimensions was not required and model complexity was not further increased. The wetted stream bottom area in natural streams is dynamic, but increasing the wetted area does not necessarily increase denitrification during periods of higher flow due to the reduction in residence time. As stream flow and depth increase, the amount of time that $\mathrm{NO}_{3}-\mathrm{N}$ rich water would be exposed to sites suitable for denitrification decreases, so an increase in the actual wetted stream bottom area does not always indicate an increased removal of nitrogen via denitrification. Having a constant stream bottom area in the model may compensate for the effect of water residence time on in-stream denitrification.

When using the alternate equation to calculate the mass of nitrogen removed from the system through in-stream denitrification, the mass transfer coefficient was the only model input that was changed in the calibration process. An initial $\rho$ was chosen based on values found in published results of many previous studies (Birgand et al., 2007). The calibration results were evaluated based on visual comparison to the observed data, the $R^{2}$ value, and the Nash-Sutcliffe (NS) efficiency. An NS efficiency greater than zero indicates that the model output is better than using the mean of the observed data (Nash and Sutcliffe, 1970). The $\rho$ was adjusted to produce simulated $\mathrm{NO}_{3}-\mathrm{N}$ dynamics that most closely followed the dynamics of the observed concentrations along with acceptable goodness-of-fit values.

\subsection{Model validation}

Following calibration of the model, the model was validated for the same catchment for 2001 to evaluate the performance of the alternate equation. All of the parameters that were set during the calibration period remained the same for the validation period. The only thing that was changed was the time series of input data (e.g., temperature, precipitation, etc.) that was used in the simulations. The validation results were evaluated based on visual inspection, the $R^{2}$ value, and the NS efficiency. 


\subsection{Sensitivity analysis}

An added input that is not easily defined is not generally thought of as a model improvement. One drawback of using the mass transfer coefficient alternate equation in the INCA-N model is that it requires an added input of stream bottom area. The method used in this work to estimate the stream bottom area is quick and practical for modeling, but has a high degree of uncertainty. The amount of uncertainty varies depending on the data available for the catchment to be modeled. To better understand the impact that uncertainty in the estimated stream bottom area may have on the results, a simple sensitivity analysis was carried out. In this sensitivity analysis the stream bottom area used in the model for each sub-catchment was varied by 20 and $40 \%$. The impact of varying stream bottom area on the simulated $\mathrm{NO}_{3}-\mathrm{N}$ concentrations and the mass of nitrogen removed via denitrification were evaluated.

\section{Results and discussion}

\subsection{Model calibration}

The outputs from the INCA-N model were compared to the results obtained using the alternate in-stream denitrification equation for the calibration period in Fig. 1a. Based on a visual inspection of the results, the alternate equation simulated the lowest observed concentration in 2004 better than the existing equation. The remainder of the results varied with each equation modeling certain observed concentrations better than the other. The observed concentrations above $3 \mathrm{mg} \mathrm{L}^{-1}$ prior to May 2004 were simulated better by the alternate equation, but this may have been caused by an incorrect simulation of flow dynamics just prior to this event (Fig. 1b). The simulated flow was closer to the observed flow for the event in February 2004 where the $\mathrm{NO}_{3}-\mathrm{N}$ concentration simulated using the alternate equation was closer to the observed concentration than the simulation using the current equation. This may be an example of the simulated mass of nitrogen removed via in-stream denitrification being incorrectly inflated in the current model due to an increase in the mass of $\mathrm{NO}_{3}-\mathrm{N}$ in the stream. At the peak concentration the simulated mass of $\mathrm{NO}_{3}-\mathrm{N}$ in the stream was more than six times higher than prior to the event when using the current equation in the INCA-N model. The mass of $\mathrm{NO}_{3}-$ $\mathrm{N}$ increased by more than six times when the concentration increased only two times its pre-storm value because the volume of water in the stream also increased. The simulated mass of nitrogen removed via denitrification with the current equation was more than six times higher at the concentration peak when compared to the mass of nitrogen removed via denitrification at the pre-storm low concentration. The simulated mass of nitrogen removed via in-stream denitrification at the peak concentration increased only three times that of
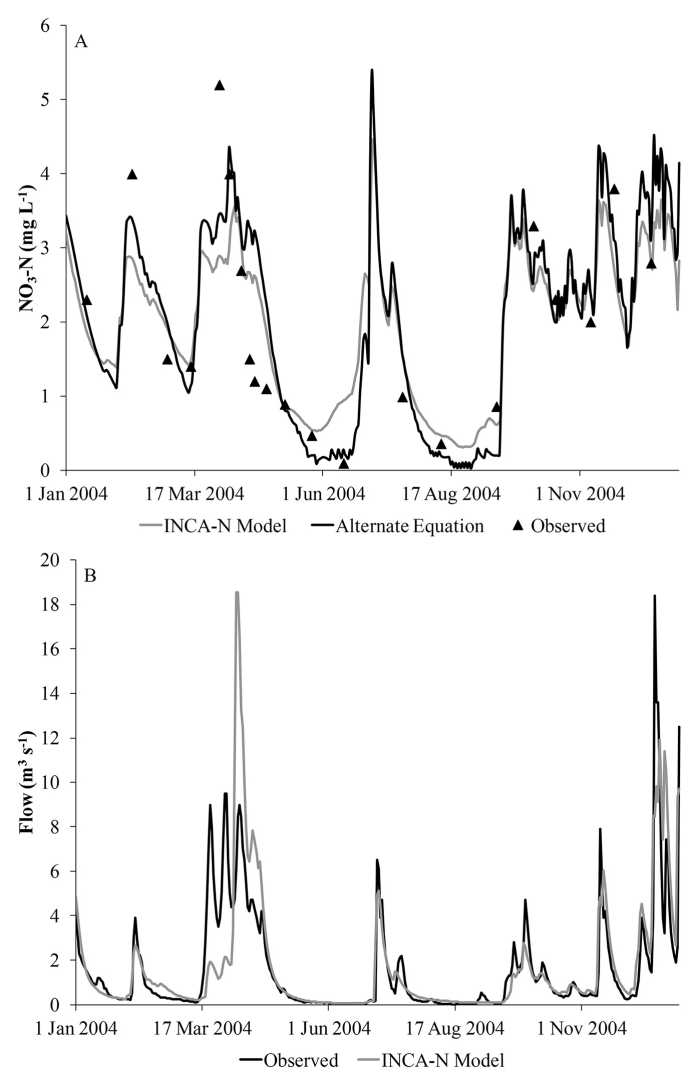

Fig. 1. (A) Graph comparing the INCA-N model results to the results with the alternate equation for the calibration period in 2004 . (B) Graph of the simulated and observed flows for the calibration period in 2004.

the value at the minimum concentration when using the alternate equation.

These results show that the alternate equation simulates lower $\mathrm{NO}_{3}-\mathrm{N}$ concentrations than the existing equation during the portions of the growing season with little flow. The lower rate of in-stream denitrification simulated by the current model during these periods is caused by the rate of denitrification being based on the low simulated mass of $\mathrm{NO}_{3}-\mathrm{N}$ in the stream. The low removal of nitrogen via in-stream denitrification using the current method of modeling the process and the low volume of water in the reach result in elevated concentrations (Eq. 3). It is possible that during this low flow period, the simulated volume of water in the reach was too low. An increase in the simulated volume would result in a lower $\mathrm{NO}_{3}-\mathrm{N}$ concentration due to dilution. Changes in the hydrologic portion of the model would also impact the results of the alternate equation, but a change in the calibrated mass transfer coefficient could potentially be used to compensate for the changes. It is possible that the lower simulated $\mathrm{NO}_{3}-\mathrm{N}$ concentrations during the periods with lower flow rates are a result of a constant stream bottom area being used. During these periods the stream bottom area may be too high 
when compared to the actual stream and the simulated mass of nitrogen removed via in-stream denitrification may be too high.

Using the alternate equation had a negligible impact on the goodness-of-fit values of the modeled results when compared to the observed concentrations. The original INCA-N equation produced an $R^{2}$ value of 0.63 and an NS of 0.60 when comparing the observed $\mathrm{NO}_{3}-\mathrm{N}$ concentrations to the simulated concentrations. The alternate equation using the mass transfer coefficient produced an $R^{2}$ value of 0.63 and an NS of 0.61 . The lack of improved goodness-of-fit values is indicative of the observation that each equation produced more accurate simulations at different points during the year.

The calibrated rate of in-stream denitrification in the INCA-N model was $0.145 \mathrm{day}^{-1}$. This resulted in a total nitrogen removal due to in-stream denitrification of $65000 \mathrm{~kg}$ for the 12 month modeling period in the 4 sub-catchments. This was equivalent to $30 \%$ of the nitrogen that entered the stream being retained by in-stream processes. A mass transfer coefficient of $0.21 \mathrm{mday}^{-1}$ was used in the alternate equation as it produced the best results through calibration. The nitrogen removal via in-stream denitrification was $44000 \mathrm{~kg}$ or $20 \%$ of the total nitrogen that entered the stream for the alternate equation. The mass of nitrogen removed through denitrification was lower using the alternate equation because it did not simulate as much nitrogen removal during periods of high flow. The lower in-stream retention simulated by the alternate equation was closer to values of between 5 and $15 \%$ that have been estimated in Finnish catchments (Lepistö et al., 2006; Martikainen et al., unpublished). The mass transfer coefficient of $0.21 \mathrm{~m} \mathrm{day}^{-1}$ used in this model application was within the range of plausible values based on the review by Birgand et al. (2007) as most of the values in the review were below $0.3 \mathrm{~m} \mathrm{day}^{-1}$.

\subsection{Model validation}

The models using the two different equations were validated for 2001 and the results are shown in Fig. 2. The validation shows that neither the current model nor the model with the alternate equation adequately simulated the observed $\mathrm{NO}_{3}-$ $\mathrm{N}$ concentrations prior to June 2001 or after August 2001. This indicates that either the mass of $\mathrm{NO}_{3}-\mathrm{N}$ input to the stream was too high or the volume of water simulated in the stream was too low during these periods. During the summer low flow periods, the alternate equation was able to simulate the lowest $\mathrm{NO}_{3}-\mathrm{N}$ concentrations better than the equation currently used in the INCA-N model. This could be a result of the uncertainty related to other simulated processes (e.g., leaching) being lower during this period of time and an improved simulation of in-stream denitrification being shown by the improved simulation of $\mathrm{NO}_{3}-\mathrm{N}$ concentrations. The low input of flow to the stream through surface water and groundwater would result in lower $\mathrm{NO}_{3}-\mathrm{N}$ inputs to the stream; therefore the process most likely to impact

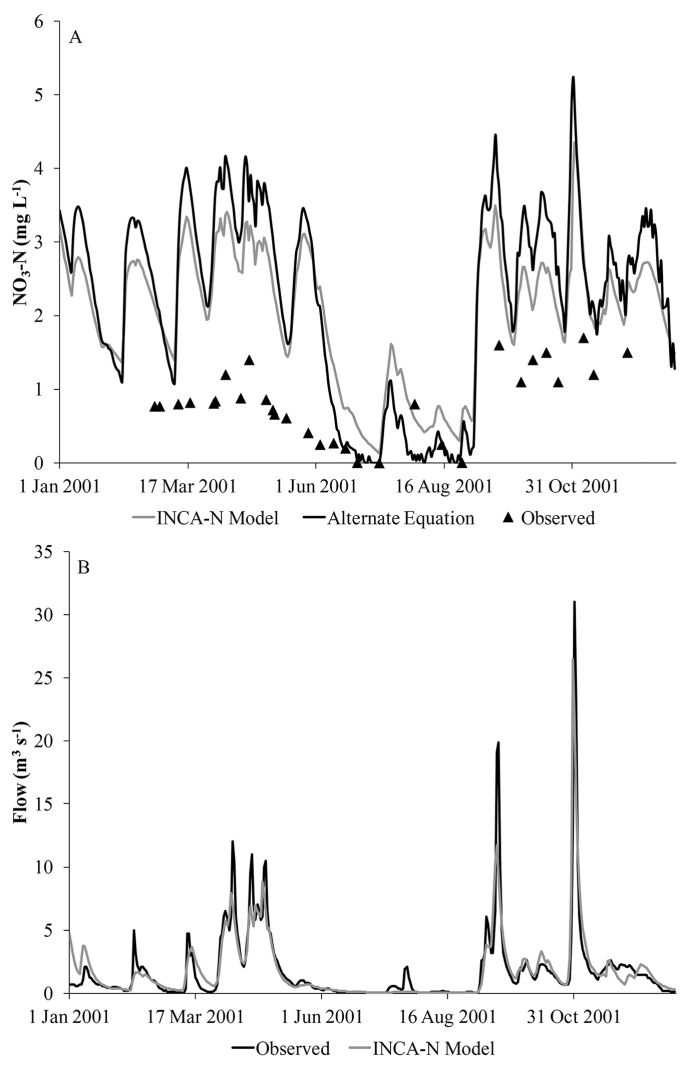

Fig. 2. (A) Graph comparing the INCA-N model results to the results with the alternate equation for the validation period in 2001 . (B) Graph of the simulated and observed flows for the validation period in 2001.

the in-stream $\mathrm{NO}_{3}-\mathrm{N}$ concentrations during this time was in-stream denitrification. Since in-stream denitrification was likely the dominant process an improved simulation of $\mathrm{NO}_{3}-$ $\mathrm{N}$ concentrations could be attributed to an improved simulation of denitrification. Basing the simulated mass of nitrogen removed via denitrification on the mass of $\mathrm{NO}_{3}-\mathrm{N}$ in the stream accounts for the dynamics of lower peak concentrations and higher minimum concentrations simulated by the current equation when compared to the alternate equation. The $R^{2}$ values were similar with values of 0.45 and 0.48 for the current equation and alternate equation respectively. The NS efficiency in both cases was below zero.

Although Birgand et al. (2007) recommended using the mass transfer coefficient when the $\mathrm{NO}_{3}-\mathrm{N}$ concentrations were greater than $1 \mathrm{~m} \mathrm{~L}^{-1}$, it appears that the alternate equation, using the mass transfer coefficient, simulates in-stream denitrification during low flow and low $\mathrm{NO}_{3}-\mathrm{N}$ concentration conditions better than the current equations used in the INCA-N model. It is possible that a downward flux of $\mathrm{NO}_{3}-$ $\mathrm{N}$ continued to occur at concentrations below $0.5 \mathrm{mg} \mathrm{L}^{-1}$ and the alternate equation was still valid in this catchment. 


\subsection{Sensitivity analysis}

The impact of varying the stream bottom area by $20 \%$ on the $\mathrm{NO}_{3}-\mathrm{N}$ concentrations during the calibration period is shown in Fig. 3a. The average of the $\mathrm{NO}_{3}-\mathrm{N}$ concentration increased $0.2 \mathrm{mg} \mathrm{L}^{-1}$ when the stream bottom area was decreased by $20 \%$ and decreased $0.1 \mathrm{mg} \mathrm{L}^{-1}$ when the stream bottom area was increased by $20 \%$. The maximum difference in $\mathrm{NO}_{3}-\mathrm{N}$ concentration based solely on changing the stream bottom area was a decrease in concentration of $0.4 \mathrm{mg} \mathrm{L}^{-1}$ when the $\mathrm{NO}_{3}-\mathrm{N}$ concentration was decreasing following the spike in July 2004. The simulated mass of nitrogen removed via in-stream denitrification was 44000 , 49000 , and $39000 \mathrm{~kg}$ for the calibrated alternate equation model, the model with the stream bottom area increased by $20 \%$, and the model with stream bottom area decreased by $20 \%$, respectively. These results indicate that a $20 \%$ change in the stream bottom area does not result in a $20 \%$ change in the simulated in-stream denitrification and that a decrease in the stream bottom area, as would be expected during the low flow periods, still does not raise the $\mathrm{NO}_{3}-\mathrm{N}$ concentrations simulated by the alternate equation to the level of those simulated using the current equation in the model. Figure $3 \mathrm{~b}$ shows that a change in stream bottom area of $40 \%$ does not account for the difference between the current equation used in the INCA-N model and the alternate equation, which indicates the influence of basing the mass of nitrogen removed via in-stream denitrification on the mass of $\mathrm{NO}_{3}-\mathrm{N}$ in the stream versus the $\mathrm{NO}_{3}-\mathrm{N}$ concentration. Uncertainty in the stream bottom area measurement can cause changes in the model results, but errors caused by inaccurate measurement of the stream bottom area are smaller than the errors in other portions of the model.

Using the alternate equation in INCA-N may improve the simulation of $\mathrm{NO}_{3}-\mathrm{N}$ concentrations during the low-flow portions of the growing season, but may not be addressing the root cause of the overestimation of $\mathrm{NO}_{3}-\mathrm{N}$ concentrations. Improvements in the simulation of the volume of water in the stream during the summer could produce similar results. The validation period also shows that the mass of $\mathrm{NO}_{3}-\mathrm{N}$ going into the stream is overestimated and needs improvement.

\section{Conclusions}

Using a short period of time to test the proposed in-stream denitrification equation is not as accurate as doing a multiple year calibration in the model, but this work shows that the use of alternate equation results in lower simulated $\mathrm{NO}_{3}-$ $\mathrm{N}$ concentrations during the growing season when compared to the alternate equation. During the calibration period the alternate equation shows promise for being able to better simulate peak concentrations. The influence of other factors such as the incorrect simulation of the volume of water in the reach or the mass of $\mathrm{NO}_{3}-\mathrm{N}$ input to the stream also

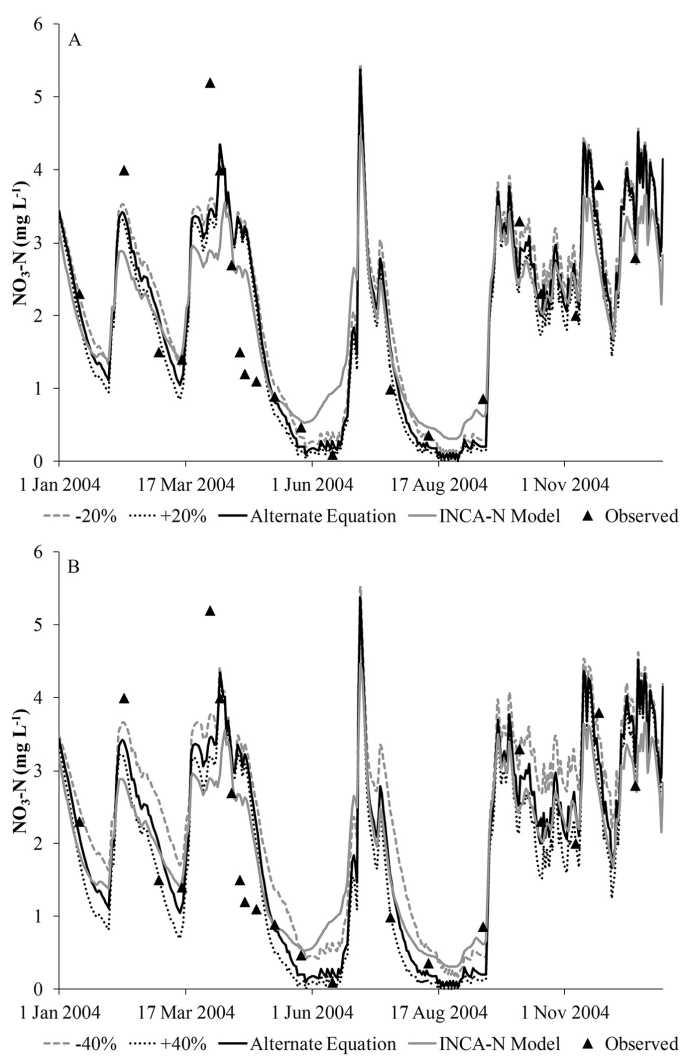

Fig. 3. (A) Graph comparing the INCA-N model results to the results with the alternate equation and the alternate equation with the stream bottom area varying $\pm 20 \%$ for the calibration period. (B) Graph comparing the INCA-N model results to the results with the alternate equation and the alternate equation with the stream bottom area varying $\pm 40 \%$ for the calibration period.

play a major role in the inaccuracy of the simulated $\mathrm{NO}_{3}-$ $\mathrm{N}$ concentrations. Further investigation is required into the simulation of the other factors controlling in-stream $\mathrm{NO}_{3}-$ $\mathrm{N}$ concentrations, but this work provides evidence that the mass transfer coefficient equation should be considered as an alternate method of modeling the in-stream denitrification in the INCA-N model if the problem of simulating low $\mathrm{NO}_{3}-\mathrm{N}$ concentrations during the growing season persists after other factors are investigated.

Acknowledgements. The authors would like to thank the two anonymous reviewers and the editor for their helpful comments, which greatly improved this technical note. This material is based upon work supported by the National Science Foundation under grant no. DGE-0750733 and by the EU REFRESH project (FP7-ENV-2009-1/244121).

Edited by: A. Butturini 


\section{References}

Birgand, F., Skaggs, R. W., Chescheir, G. M., and Gilliam, J. W.: Nitrogen removal in streams of agricultural catchments - A literature review, Crit. Rev. Environ. Sci. Tech., 37, 381-487, 2007.

Etheridge, J. R., Lepistö, A., Granlund, K., Rankinen, K., Birgand, F., and Burchell, M. R.: Reducing uncertainty in the calibration and validation of the INCA-N model by using soft data, Hydrol. Res., 45, 73-88, 2014.

Granlund, K., Rankinen, K., and Lepistö, A.: Testing the INCA model in a small agricultural catchment in southern Finland, Hydrol. Earth Syst. Sci., 8, 717-728, doi:10.5194/hess-8-717-2004, 2004.

Jarvie, H. P., Wade, A. J., Butterfield, D., Whitehead, P. G., Tindall, C. I., Virtue, W. A., Dryburgh, W., and McGraw, A.: Modelling nitrogen dynamics and distributions in the River Tweed, Scotland: an application of the INCA model, Hydrol. Earth Syst. Sci., 6, 433-454, doi:10.5194/hess-6-433-2002, 2002.

Lepistö, A., Granlund, K., Kortelainen, P., and Räike, A.: Nitrogen in river basins: Sources, retention in the surface waters and peatlands, and fluxes to estuaries in Finland, Sci. Total. Environ., 365, 238-259, 2006.

Lepistö, A., Huttula, T., Bärlund, I., Granlund, K., Härmä, P., Kallio, K., Kiirikki, M., Kirkkala, T., Koponen, S., Koskiaho, J., Kotamäki, N., Lindfors, A., Malve, O., Pyhälahti, T., Tattari, S., and Törmä, M.: New measurement technology, modelling and remote sensing in the Säkylän Pyhäjärvi area - Catchlake, Reports of Finnish Environment Institute, Helsinki, Finland, 15, 2008.

Nash, J. E. and Sutcliffe, J. V.: River flow forecasting through conceptual models part I - a discussion of principles, J. Hydrol., 10, 282-290, 1970.

O'Shea, L. and Wade, A. J.: Controlling nitrate pollution: An integrated approach, Land Use Policy, 26, 799-808, 2009.
Rankinen, K., Karvonen, T., and Butterfield, D.: An application of the GLUE methodology for estimating the parameters of the INCA-N model, Sci. Total Environ., 365, 123-139, 2006.

Rankinen, K., Granlund, K., Futter, M. N., Butterfield, D., Wade, A. J., Skeffington, R., Arvola, L., Veijalainen, N., Huttunen, I., and Lepistö, A.: Controls on inorganic nitrogen leaching from Finnish catchments assessed using a sensitivity and uncertainty analysis of the INCA-N model, Boreal Environ. Res., 18, 373386, 2013.

Reddy, K. R., Patrick, W. H., and Phillips, R. E.: The role of nitrate diffusion in determining the order and rate of denitrification in flooded soil: I. Experimental results, Soil Sci. Soc. Am. J., 42, 268-272, 1978.

Wade, A. J., Durand, P., Beaujouan, V., Wessel, W. W., Raat, K. J., Whitehead, P. G., Butterfield, D., Rankinen, K., and Lepisto, A.: A nitrogen model for European catchments: INCA, new model structure and equations, Hydrol. Earth Syst. Sci., 6, 559-582, doi:10.5194/hess-6-559-2002, 2002.

Wade, A. J., Butterfield, D., and Whitehead, P. G.: Towards an improved understanding of the nitrate dynamics in lowland, permeable river-systems: Applications of INCA-N, J. Hydrol., 330, 185-203, 2006.

Wade, A. J., Jackson, B. M., and Butterfield, D.: Overparameterised, uncertain 'mathematical marionettes' - How can we best use catchment water quality models? An example of an 80-year catchment-scale nutrient balance, Sci. Total Environ., 400, 52-74, 2008.

Whitehead, P. G., Wilson, E. J., and Butterfield, D.: A semidistributed Integrated Nitrogen model for multiple source assessment in Catchments (INCA): Part I - model structure and process equations, Sci. Total Environ., 210, 547-558, 1998. 